\title{
EVALUASI PASCA HUNI ASPEK FUNGSIONAL PADA BANGUNAN RUMAH SUSUN SEDERHANA SEWA (RUSUNAWA) UNIVERSITAS TANJUNGPURA
}

\author{
O'i Prasesti' ${ }^{1}$, Muhammad Ridha Alhamdani ${ }^{2}$, Rudiyono $^{3}$ \\ ${ }^{1}$ Mahasiswa, Jurusan Arsitektur, Fakultas Teknik, Universitas Tanjungpura. \\ oiprasesti652@gmail.com \\ ${ }^{2}$ Jurusan Arsitektur, Fakultas Teknik, Universitas Tanjungpura \\ ${ }^{3}$ Jurusan Arsitektur, Fakultas Teknik, Universitas Tanjungpura
}

Naskah diajukan pada: 14 Agustus 2021

Naskah revisi akhir diterima pada: 17 Agustus 2021

\begin{abstract}
Abstrak
Kebijakan dan strategi pembangunan rumah susun telah dicanangkan di berbagai Kota salah satunya di Kota Pontianak yang diperuntukkan bagi masyarakat umum maupun mahasiswa. Rusunawa yang ada di Pontianak salah satunya Rusunawa Universitas Tanjungpura yang disewakan untuk mahasiswa yang dibangun pada tahun 2009. Berdasarkan hal tersebut maka perlu diadakan Evaluasi Pasca Huni bangunan yang telah dipakai untuk beberapa waktu. Penelitian ini bertujuan untuk mengidentifikasi dan mengevaluasi bangunan Rusunawa Universitas Tanjungpura yang ditinjau pada aspek fungsional serta penerapannya dalam solusi desain. Pendekatan penelitian yang digunakan adalah penelitian kualitatif dan kuantitatif. Metode penelitian yang digunakan adalah space syntax dan place centered mapping. Hasil penelitian menunjukkan hasil analisis connectivity pada space syntax menunjukkan nilai yang rendah pada area ruang jemur dan ruang dapur serta analisis intergration pada space syntax menunjukkan nilai yang rendah pada sirkulasi bangunan area 1, 2, 3, dan 4. Data place centered mapping menunjukkan adanya aktivitas yang dilakukan penghuni secara rutin pada bangunan. Hal ini menunjukkan perubahan fungsi ruang dan berpengaruh pada dimensi ruang. Evaluasi pasca huni menunjukkan adanya perubahan fungsi ruang, akses sirkulasi, dimensi ruang pada bangunan. Berdasarkan hasil analisis serta evaluasi pasca huni, maka usulan desain juga berfokus pada variabel yang aspek fungsional yaitu sirkulasi, dimensi, fleksibilitas dan perubahan fungsi ruang.
\end{abstract}

Kata-kata Kunci: Evaluasi Pasca Huni, Aspek Fungsional, Rusunawa Universitas Tanjungpura

\begin{abstract}
Policies and strategies for the construction of flats have been launched in various cities, one of which is in Pontianak which is intended for the general public and students. One of the Rusunawa in Pontianak is the Tanjungpura University Flat which is rented out for students which was built in 2009. Based on this, it is necessary to carry out a Post-Work Evaluation of the building that has been used for some time. This study aims to identify and evaluate the Rusunawa building of Tanjungpura University in terms of functional aspects and its application in design solutions. The research approach used is qualitative and quantitative research. The research method used is spatial syntax and placecentred mapping. The results showed that the results of connectivity analysis in spatial syntax showed low values in the drying room and kitchen area and integration analysis on spatial syntax showed low values in building circulation areas 1, 2, 3, and 4. Place centered mapping data showed activity. That residents routinely do on the building. This indicates a change in the function of space and affects the dimensions of space. The post-occupancy evaluation shows a change in the function of space, access to circulation, and the dimensions of space in the building. Based on the results of postoccupancy analysis and evaluation, the design proposal also focuses on variables with functional aspects, namely circulation, dimensions, flexibility and changes in space function.
\end{abstract}

Keywords: Post-Occupational Evaluation, Functional Aspects, Dormitory Tanjungpura University 


\section{Pendahuluan}

Gaya hidup mahasiswa yang semakin meningkat menuntut hunian yang ada menjadi semakin berkualitas. Hal ini berlaku di kota besar termasuk Kota Pontianak. Hunian untuk mahasiswa sudah bukan lagi sekedar tempat untuk tidur saja melainkan untuk beraktivitas sehari-hari seperti mandi, makan, dan kerja bahkan untuk berkumpul bersama beberapa orang (Harianto, 2016). Infrastruktur dalam pendidikan juga dibutuhkan untuk membantu aktivitas pendidikan mahasiswa itu sendiri. Dilihat dari kebutuhan tersebut, infrastruktur yang dikembangkan beberapa universitas adalah pengembangan Rusunawa (rumah susun sederhana sewa) bagi mahasiswa dengan biaya yang minimal. Pembangunan Rusunawa secara fisik berfungsi sebagai pelengkap kebutuhan dasar sebagai tempat berlindung dari gangguan luar para penghuninya (Mulia, 2012).

Saat ini kebijakan dan strategi pembangunan rumah susun telah dicanangkan diberbagai Kota salah satunya di Kota Pontianak yang diperuntukan bagi masyarakat umum maupun mahasiswa. Rusunawa yang ada di Pontianak sebanyak 3 bangunan, yaitu Rusunawa Polnep, Rusunawa Nipah Kuning Dalam yang baru selesai dibangun pada tahun 2019, dan Rusunawa Universitas Tanjungpura yang disewakan untuk mahasiswa yang dibangun pada tahun 2009. Fenomena permasalahan yang terjadi pada bangunan Rusunawa pada umumnya didasari terkait tentang fisik bangunan mulai dari sirkulasi udara, minimnya ruang gerak pada penghuni, koridor sempit dan panjang, lingkungan yang kurang memadai. Menurut Sudibyo dalam Prawitasari (2020) Evaluasi Pasca Huni diartikan sebagai kegiatan berupa peninjauan kembali (evaluasi) terhadap bangunan-bangunan atau lingkungan binaan yang telah dihuni. Evaluasi Pasca Huni memiliki tiga aspek yang menjadi performa konsep bangunannya; Pertama aspek fungsional, dimana segala aspek bangunan (pengaturan pada lingkungan hunian) yang secara langsung mendukung kegiatan pemakai dengan segala atributnya (perorangan dan kelompok).

Oleh karena itu peneliti tertarik untuk melakukan Evaluasi Pasca Huni dengan teknik lain yang mempelajari, menganalisis, serta mengevaluasi menggunakan metode space syntax serta place centred mapping. Adanya kedua metode yang digunakan dapat menganalisis permasalahan terhadap variabel aspek fungsional yang telah ditentukan sehingga dalam hal ini perlunya ukuran, perhitungan, serta simulasi melalui denah bangunan dan melakukan pemetaan berdasarkan tempat pergerakan manusia pada suatu periode waktu tertentu di bangunan Rusunawa Univesitas Tanjungpura. Penelitian ini diharapkan bisa menjadi usulan dalam upaya evaluasi pasca huni terkait bangunan Rusunawa yang telah digunakan sebagai tempat tinggal. Berdasarkan hasil penelusuran literatur yang ada, sejauh ini penelitian Evaluasi Pasca Huni terhadap aspek fungsional pada bangunan Rusunawa Universitas Tanjungpura belum pernah dilakukan. Berangkat dari umur bangunan yang telah mencapai 12 tahun maka hal ini juga yang menjadi tolak ukur bahwa bangunan tersebut perlu dilakukan Evaluasi Pasca Huni sehingga mendapatkan hasil temuan terhadap aspek fungsional pada bangunan Rusunawa Universitas Tanjungpura.

\section{Kajian Pustaka \\ Apartemen}

Menurut Fatila (2019) apartemen dapat merupakan bagunan yang terdiri dari beberapa blok hunian yang disusun dengan bentuk bertingkat, serta memiliki fasilitas kebutuhan ruang yang sama, untuk mengatasi masalah kepadatan tingkat hunian dan keterbatasan lahan di perkotaan. Apartemen juga diartikan sebagai gedung bertingkat yang dibangun dalam suatu lingkungan, terbagi atas bagianbagian yang distrukturkan secara fungsional dalam arah vertikal dan horizontal dan merupakan satuan-satuan yang dapat dimiliki dan digunakan secara terpisah yang dilengkapi dengan bagian bersama, tanah bersama dan benda bersama (pasal 1 UURS no.16 tahun 1985). Berdasarkan Tipe Pengelolaan menurut Akmal (2007) dalam Fatila (2019) apartemen terdiri dari beberapa tipe hunian, yaitu: 
1. Serviced Apartment, merupakan apartemen yang atur secara menyeluruh oleh menajemen tertentu.

2. Apartemen Milik Sendiri, merupakan apartemen yang dijual dan dapat dibeli oleh pihak perorangan.

3. Apartmen Sewa atau biasanya disebut Rumah Susun Sewa, merupakan apartemen yang disewa oleh individu tanpa penyelayanan khusus

\section{Evaluasi Pasca Huni}

Pengertian Evaluasi Pasca Huni/Post Occupancy Evaluation menurut beberapa sumber mengatakan bahwa teori ini merupakan sebuah pendekatan mengenai peninjauan atau pengkajian (evaluasi) terhadap bangunan-bangunan yang telah dihuni dan ditempati selama beberapa tahun. Kegiatan evaluasi pasca huni selain menilai kinerja bangunan berupa aspek teknik, aspek fungsional dan aspek perilaku (Natalia, 2019). Menurut Presier dalam Pandelaki (2015) terdapat 3 aspek parameter kinerja bangunan yang dapat diidentifikasi dan diaplikasikan kedalam Evaluasi Pasca Huni, yaitu aspek teknik, aspek fungsional dan aspek perilaku.

Aspek Teknik Terdapat dalam aspek bangunan yang terdiri dari unsur kesehatan, keselamatan, keamanan bangunan yang dapat dijumpai pada keselamatan dari bahaya kebakaran, struktur bangunan, dinding bangunan, ventilasi, listrik, sanitasi, atap, interior, pencahayaan dan akustik.

Aspek Fungsional Aspek fungsional berhubungan dengan aktivitas di dalam gedung yang dipengaruhi oleh bentuk atau setting ruang gedung, jenis aktivitas yang berkangsung, pola aktivitas, sirkulasi, faktor manusia yaitu melihat kelengkapan fasilitas ruang, ukuran pada ruang, lokasi bangunan, serta bagaimana pengguna memanfaatkan ruangnya (Wijaya, 2018). Ada 4 variabel aspek fungsonal menurut Sudibyo (1989) antara lain adalah:

a. Faktor manusia, akan terkait dalam segi perancangan dan standar. Tingkat kesesuaiannya antara konfigurasi, material dan ukuran terhadap pemakaiannya. Sebagai salah satu pedoman pabrikasi sering menimbulkan permasalahan jika ditetapkan pada dua kelompok masingmasing yang tidak sama.

b. Dimensi, menurut bagian dimensi berkenaan dengan ukuran ruang dan furniture. Dimensi pada bangunan akan disesuaikan dengan standar ruang yang telah ditetapkan dalam aturan SNI yang berlaku untuk diterapkan langsung pada ruangan.

c. Sirkulasi merupakan salah satu fungsi bangunan. Sirkulasi pada bangunan dilihat dari indikator alur/akses, tipe sirkulasi dan jenis sirkulasi. Tidak jarang kesalahan pengaturan sirkulasi menyebabkan ada daerah yang sepi dan ada daerah yang padat. Pengaturan sirkulasi dapat mempengaruhi arah kemana penghuni akan berjalan dan dapat mencapai semua fasilitas secara merata (Kusumastuty, 2016).

d. Fleksibilitas dan perubahan fungsi. Banyak bangunan yang mengalami perubahan fungsi. Evaluasi terhadap perubahan fungsi, susunan organisasi dan kegiatan dapat mempengaruhi rancangan tata luar dan prasarana.

Aspek Perilaku adalah unsur sosial masyarakat dan psikologis tingkat kepuasan bagi penghuni, meliputi aspek privasi dan interaksi antar penghuni bangunan, kognisi, pemahaman perancangan bangunan, rasa kepemilikan, persepsi lingkungan, dan orientasi lingkungan.

\section{Behaviour Mapping}

Behavior Mapping merupakan gambaran perilaku dan penggambaran pemakainya serta penentuan perilaku pada pusat fisiknya (phsycal locus) (Kurniadi et al., 2020). Pemetaan perilaku merupakan salah satu teknik survei sebagai penyajian arsitektur perilaku, menurut Sommer (1986) dalam Siregar (2014) bahwa pemetaan perilaku dapat digambarkan dalam bentuk sketsa atau diagram mengenai suatu area dimana manusia melakukan berbagai kegiatannya.

Place Centered Mapping merupakan teknik yang digunakan untuk mengetahui manusia atau sekelomopok manusia memanfaatkan, menggunakan, atau mengakomodasikan perilakunya dalam 
suatu situasi waktu dan tempat tertentu (Fitria, 2018). Peneliti menggunakan peta dasar dan harus kenal dengan situasi tempat atau area yang diamati. Menurut Sommer (1980) Place Centered Mapping berfungsi untuk melihat perilaku manusia dengan titik lokasi pada peta, mengidentifikasikan jenis, pola dan tingkat aktivitas yang dilakukan, serta menunjukkan kaitan antara perilaku tersebut dengan suatu bentuk rancangan.

\section{Space Syntax}

Space Syntax menurut Hillier (2007) merupakan pengembangan teori baru terkait ruang sebagai aspek kehidupan sosial atau individu. Space syntax juga alat yang dapat memberikan hasil temuan yaitu konfigurasi ruang. Konfigurasi ruang merupakan wadah yang memiliki hubungan dimana objek-objek saling berkaitan dengan yang lainnya, sehingga akan membentuk struktur ruang pada bangunan yang dapat dimanfaatkan manusia dalam menjalankan setiap aktivitasnya (Karmilah, 2018). Pemataan Ruang dalam Space Syntax. Hillier (2012) membedakan jenis grafik tipologis dalam analisis space syntax menjadi axial dan convex. Selain memiliki bentuk yang berbeda, kedua grafik tipologis ini juga digunakan dalam skala yang berbeda.

\section{A. Visual Graph Map}

Visual Graph dapat melakukan perhitungan integrasi jalan dengan memperhatikan pergerakan dan semakin sedikitnya perubahan arah terhadap jalan akan menghasilkan ruang yang semakin terintegrasi dengan baik. Visual Graph dalam space syntax juga digunakan untuk menunjukkan visual ruang (visibilitas) dengan hubungan elemen ruang yang mempengaruhi pergerakan dan membantu memahami ruang disekitar kita (Turner, 2001).

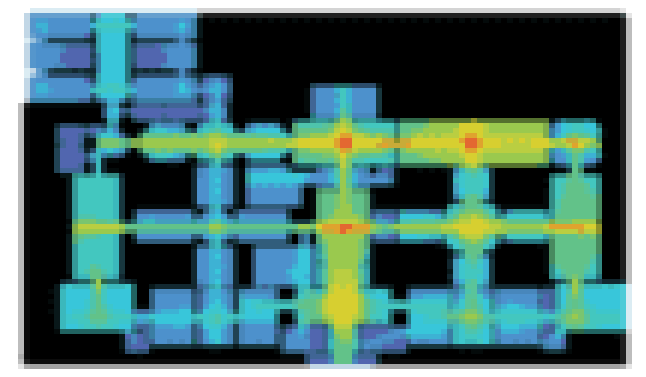

Gambar 1. Contoh Hasil Visual Graph Sumber: Varoudis, 2014

\section{B. Convex map}

Convex map digunakan dalam perhitungan skala bangunan. Berbeda dengan axial analysis yang merepresentasikan jalan dalam bentuk garis, convex map diibaratkan sebagai ruang-ruang yang direpresentasikan dalam bentuk geometris konveks tertutup yang terpisah-pisah. Bentuk geometris ini menggambarkan hubungan kedekatan antar ruang. Semakin sedikit stepdepth antar ruang maka semakin dekat jarak antar ruang tersebut.

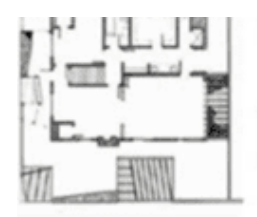

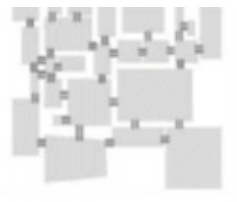

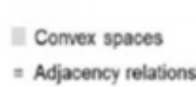

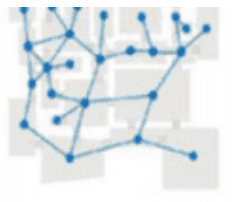

Convex map
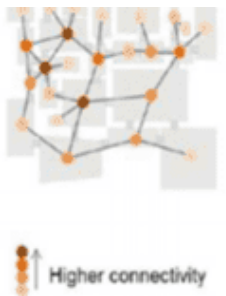
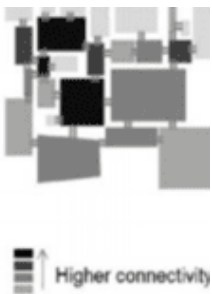

Gambar 2. Pemetaan Convex Analysis untuk Analisis Skala Bangunan Sumber: Hillier, 2012 


\section{Jenis Analisis Space Syntax}

Menurut Mutmainnah (2018) ruang dalam space syntax dipetakan sebagai jalan, kotak, kamar, taman, atau suatu ruang yang membatasinya. Suatu ruang terdapat penghalang yang mungkin membatasi akses dan atau menghalangi pandangan seperti pagar, dinding, paritisi, perabot, ataupun barang penghalang lainnya. Space syntax adalah metode yang digunakan untuk menguraikan mengenai konfigurasi ruang terkait hubungan ruang (space) dengan penghuninya (society).

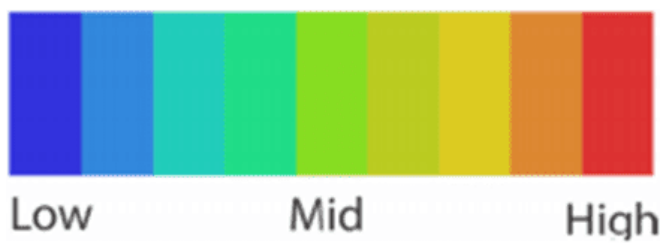

Gambar 3. Tingkatan Warna pada Analisis Space Syntax Sumber: Pinelo \& Turner, 2010

Analisis space syntax memiliki tingkatan warna mulai dari nilai rendah ditunjukan dengan adanya warna biru yang bergradasi menuju warna hijau, selanjutnya nilai menengah ditunjukkan dengan warna hijau bergradasi menuju warna kuning, kemudian nilai tertinggi ditandai dengan warna kuning menuju gradasi warna merah (Pinelo dan Turner, 2010). Menurut Hillier (2007) Konsep dasar analisis space syntax terdiri dari 3 macam perhitungan Connectivity, Integration, dan Intelligibility.

Connectivity adalah hubungan antar ruang dengan cara memperlihatkan banyaknya ruang yang secara langsung terhubung dengan ruang pengamat. Menurut Siregar (2014) Jumlah ruang yang terhubung dihitung dengan mempergunakan konsep jarak yang disebut kedalaman atau depth. Demikian dikatakan terhubung secara langsung apabila hanya memiliki jarak sebesar 1 langkah atau 1 step depth.

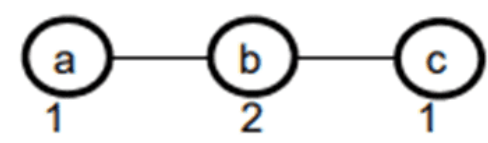

Gambar 4. Nilai Connectivity Hubungan Antar Ruang

Sumber: Siregar, 2014

Integration adalah dimensi yang mengukur posisi relatif dari masing-masing ruang terhadap ruang lainya dalam suatu konfigurasi. Intelligibility dalam space syntax menunjukkan tingkat korelasi antara pengukuran connectivity dan integration. Perhitungan ini juga melibatkan ruangruang yang tidak dapat diobservasi dari ruang pengamatan, dimana penilaian integration suatu ruang akan melibatkan seluruh ruang lainnya dalam suatu konfigurasi ruang (Hillier et al: 2007).

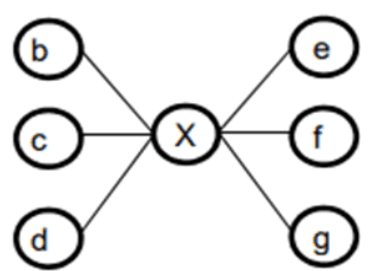

Gambar 5. Ruang Pengamatan dengan Nilai Integration yang Tinggi

Sumber: Siregar, 2014 
Pada gambar 5 bagian $\mathrm{X}$ sebagai ruang pengamatan memiliki nilai integration yang relatif lebih tinggi daripada ruang-ruang lainnya, sebab bagian $\mathrm{X}$ terhubung secara langsung dengan banyak tempat di sekitarnya. Pada gambar 5, tempat a dan tempat c sebagai ruang pengamatan memiliki nilai integration yang relatif lebih rendah sebab memiliki lebih banyak ruang antara antara lain tempat $b$ dan c. Berbeda dengan tempat b dan c yang memiliki lebih sedikit ruang antara.

Table 1. Tingkatan Keberhasilan Perhitungan Intelligibility

\begin{aligned} & \hline $\begin{array}{c}\text { Angka parameter } \\ \text { (desimal) }\end{array}$ Keterangan angka \\ & $\mathbf{0 . 0 0 - 0 . 4 0}$ Buruk / rumit \\ & \hline $\mathbf{0 . 5 0}-\mathbf{0 . 7 0}$ Cukup / sedikit \\ & rumit \\ & \hline $\mathbf{0 . 8 0}-\mathbf{1 . 0 0}$ Baik / jelas \\ & \hline\end{aligned}

Sumber: Johaness, 2014

\section{Metode}

Pendekatan penelitian yang digunakan adalah penelitian kualitatif dan kuantitatif. Penelitian kualitatif merupakan penelitian yang menggunakan metode pengumpulan data yang bersifat terarah dan data yang terkumpul cenderung berupa data teks, gambar atau objek. Penelitian kualitatif ini digunakan untuk memperoleh informasi secara mendalam terkait permasalahan aspek fungsional pada bangunan Rusunawa Universitas Tanjungpura, kemudian evaluasi seperti yang bisa dilakukan pada bangunan Rusunawa tersebut. Sedangkan penelitian kuantitaif data yang diperoleh berdasarkan hasil pengukuran berupa angka, hasil wawancara dari responden dan hasil dari metode space syntax yang telah dilakukan.

Metode Penelitian yang berjudul "Evaluasi Pasca Huni terhadap Aspek Fungsional pada Bangunan Rusunawa Universitas Tanjungpura" ini dalam pelaksanaannya merupakan penelitian Evaluasi Pasca Huni dimana menggunakan metode space syntax yang dapat menganalisis permasalahan terhadap beberapa variabel dari aspek fungsional yang telah ditentukan sehingga dalam hal ini perlunya ukuran, perhitungan, serta simulasi melalui denah bangunan serta menggunakan metode place centered mapping dengan melakukan pemetaan berdasarkan tempat pergerakan manusia pada suatu periode waktu tertentu di bangunan Rusunawa Univesitas Tanjungpura. Penelitian ini terbagi atas beberapa tahapan, diantaranya yaitu:

1. Tahap persiapan; yang dilakukan adalah memperhatikan kembali kerangka penelitian dan mempersiapkan pengumpulan data terkait bangunan Rusunawa.

2. Tahap pengumpulan data; dibagi menjadi 2 bagian yaitu pengumpulan data sekunder yang melakukan kajian pustaka untuk menghasilkan landasan teori yang digunakan untuk melakukan observasi lapangan. Kemudian pengumpulan data primer dilakukan dengan cara observasi lapangan yang meliputi pengamatan, dan dokumetasi pada bangunan Rusunawa Universitas Tanjungpura.

3. Tahap pengelolahan data dan analisis; berupa penyusunan data bangunan Rusunawa Universitas Tanjungpura yang telah diperoleh melalui wawancara serta pengambilan data pada pengelola dan penghuni Rusunawa, kemudia dilakukan analisis melalui metode space syntax untuk mengetahui pergerakan ruang dan sirkulasi dan pemetan perilaku berupa place centered mapping untuk mengetahui pergerakan manusia dalam memanfaatkan fungsi ruang pada bangunan rusunawa. 
4. Tahapan Analisis; Data yang telah dilakukan pada bangunan Rusunawa Universitas Tanjungpura, kemudian dilakukan evaluasi pasca huni terhadap bangunan, maka akan didapatkan hasil akhir berupa temuan dan rekomendasi/usulan desain.

Tabel 2. Variabel Penelitian

\begin{tabular}{cl}
\hline Variabel penelitian & \multicolumn{1}{c}{ Aspek-aspek penelitian } \\
\hline $\begin{array}{c}\text { Faktor Manusia } \\
\text { (Sudibyo, 1989) }\end{array}$ & Efisiensi Penggunaan ruang \\
\cline { 2 - 2 } $\begin{array}{c}\text { Sirkulasi } \\
\text { (Sudibyo, 1989) }\end{array}$ & Efisiensi Pergerakan orang \\
\cline { 2 - 2 } $\begin{array}{c}\text { Sirkulasi ruang dalam } \\
\text { Fleksibelitas dan perubahan } \\
\text { fungsi } \\
\text { (Sudibyo, 1989) }\end{array}$ & $\begin{array}{l}\text { Identifikasi penyesuaian dan perubahan fungsi } \\
\text { bangunan Rusunawa Universitas Tanjungpura }\end{array}$ \\
\cline { 2 - 2 } & $\begin{array}{c}\text { Analisis penyebab dan perubahan fungsi } \\
\text { bangunan Rusunawa Universitas Tanjungpura }\end{array}$ \\
\hline & Sumber: Penulis, 2021
\end{tabular}

Berdasarkan variabel yang telah dipaparkan maka pada aspek-aspek penelitian akan dilakukan berbagai metode untuk mendapatkan data, kemudian dilakukan analisis dan melakukan evaluasi agar diperoleh temuan serta usulan desain.

\section{Diagram Alir Penelitian}

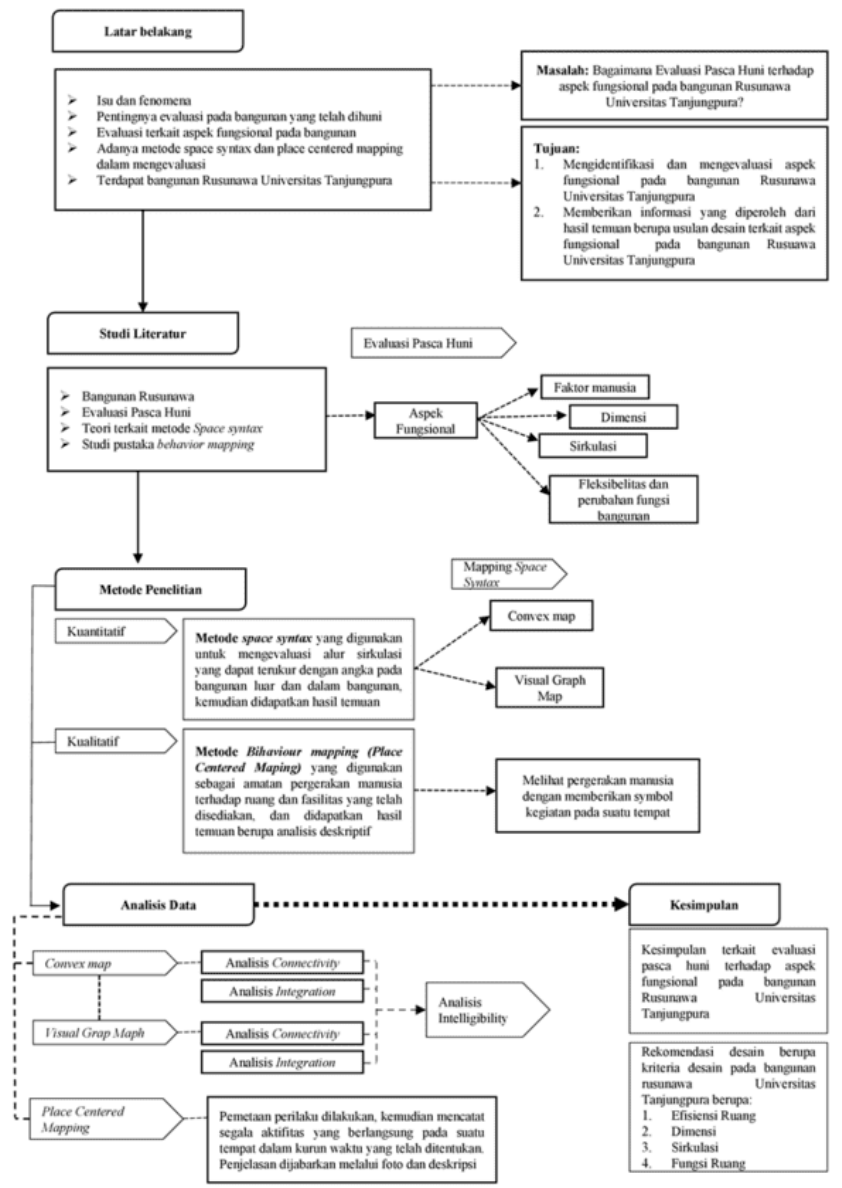

Gambar 6. Diagram Alir Penelitian

Sumber: Penulis, 2021 


\section{Hasil dan Pembahasan}

Objek penelitian ditinjau dari denah lama bangunan rusunawa Universitas Tanjungpura.
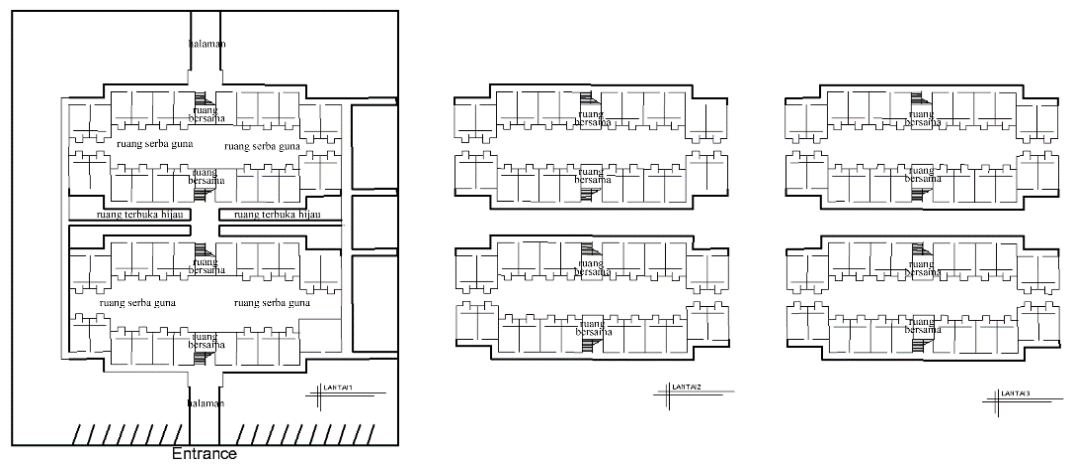

Gambar 7. Denah Eksisting Bangunan Rusunawa Universitas Tanjungpura Sumber: Penulis, 2021

Hasil dan pembahasan dibagi menjadi beberapa poin, antara lain: Analisis Connectivity, Analisis Intergration, Analisis Place Centered Mapping dan Evaluasi Pasca Huni.

\section{Analisis Connectivity}

Hasil analisis connectivity Visual Graph Map (VGA) pada bangunan Rusunawa Universitas Tanjungpura ditemukan titik ketika dianalisis memiliki nilai area yang rendah (lihat pada gambar 8 area berwarna biru). Hal ini dikarenakan nilai connectivity pada area tersebut memiliki masalah pada dimensi ruang yang tidak terpenuhi bagi penghuni, karena ruang tersebut merupakan hubungan langsung antara 2 ruang yang digunakan sebagai tempat menjemur dan memasak.

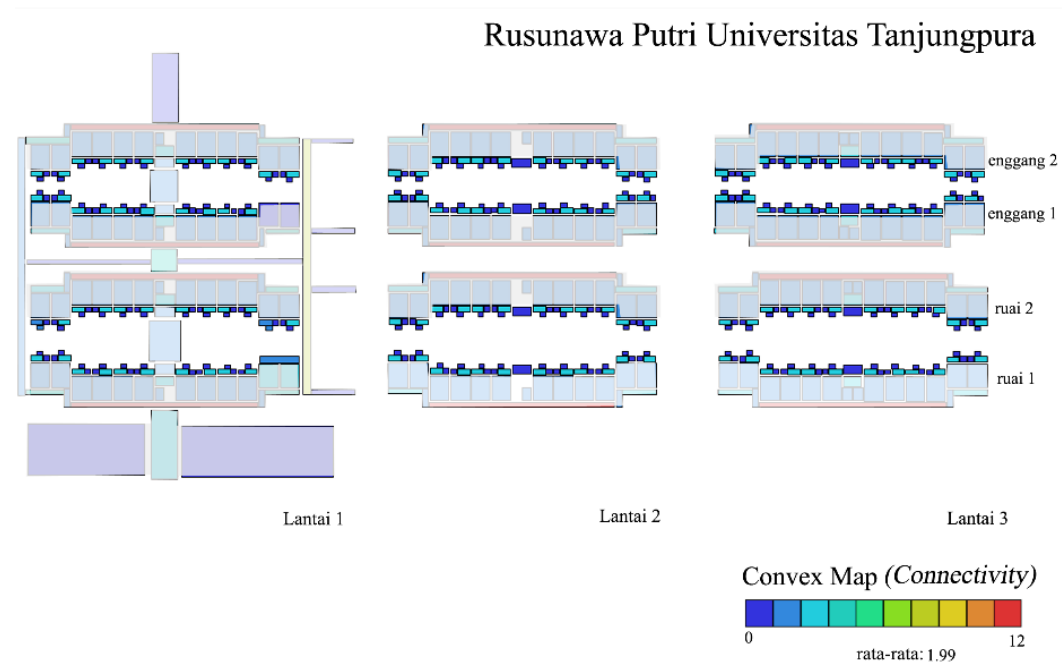

Gambar 8. Analisis Connectivity Visual Graph Maph

Sumber: Penulis, 2021

\section{Analisis Intergration}

Hasil analisis intergaration visual steph depth pada bangunan Rusunawa Universitas Tanjungpura memperlihatkan adanya masalah pada area masuk bangunan rusunawa Universitas Tanjungpura. Hal ini dikarenakan terdapat 2 pintu masuk utama dan 4 pintu masuk sekunder yang dapat mencapai bangunan rusunawa. Jumlah sirkulasi masuk yang banyak, menjadikan nilai intergration menjadi berbeda secara signifikan. 


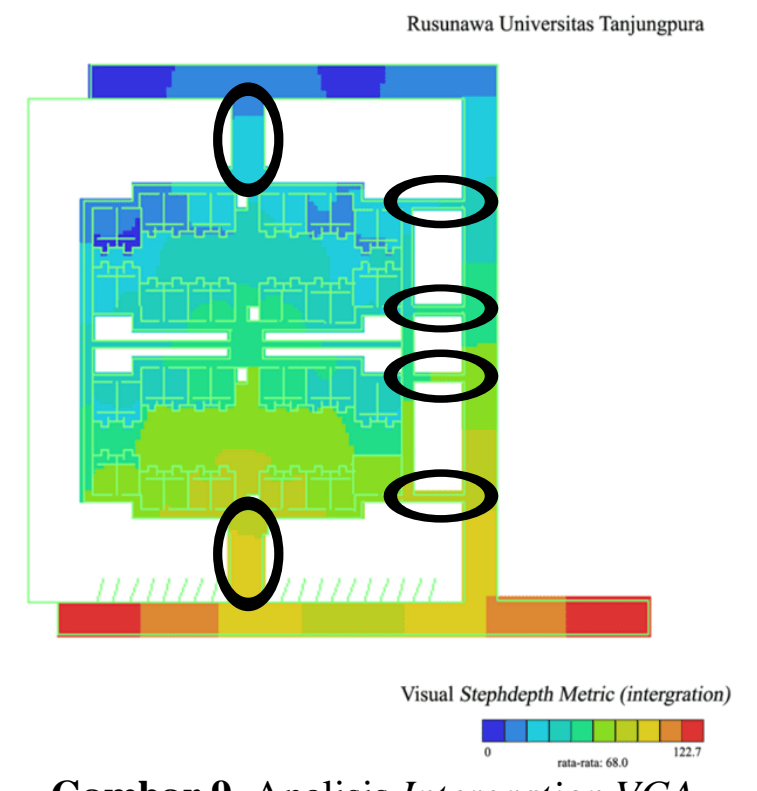

Gambar 9. Analisis Intergration VGA

Sumber: Penulis, 2021

\section{Analisis Place Centered Mapping}

Gambar 10 menunjukkan alur kegiatan pada setiap lantai bangunan Rusunawa putri Universitas Tanjungpura. Hari minggu pagi dan sore, dari data lapangan didapatkan ada beberapa ruang digunakan sesuai dengan penggunaannya, namun ada juga yang ditempati tidak sesuai penggunaannya. Lantai 1, dilihat terdapat penghuni rusunawa yang melakukan kegiatan belanja pada pagi hari pada area masuk bangunan Rusunawa Universitas Tanjungpura dan ada juga kegiatan memarkirkan kendaraan di halaman depan bangunan. Di bagian depan anak tangga bangunan terdapat penghuni dengan aktivitas menunggu yang duduk dan berdiri didepan anak tangga bangunan blok Ruai 1, sehingga hal ini dapat mengganggu penghuni lainnya untuk melewati akses utama anak tangga tersebut. Dibagian jalur sirkulasi bangunan terdapat penghuni yang berjalan, kemudian terdapat kendaraan yang melewati tempat tersebut sehingga dengan adanya kendaraan yang melintas membuat penghuni merasa kesulitan untuk melewati akses sirkulasi. Penghuni memarkirkan kendaraannya pada area ruang serbaguna, hal ini dikarenakan pada area bangunan Rusunawa putri Universitas Tanjungpura tidak menyediakan lahan parkir khusus pada bangunan menyebabkan berubahan fungsi ruang. Diwaktu yang bersamaan, terdapat aktivitas menjemur pakaian yang dilakukan pada ruang serbaguna bagian kanan bangunan, penghuni yang berada dilantai 2 dan 3 harus turun ke lantai 1 untuk menjemur pakaian. Hal ini dikarenakan area jemur pada bangunan Rusunawa hanya disediakan dengan ukuran $1 \mathrm{~m}$ x $0.80 \mathrm{~m} / \mathrm{kamar}$ penghuni yang ditempati oleh 3 penghuni. Waktu sore hari, penghuni yang menjemur pakaiannya kemudian mereka ambil dan dibawa ke ruang hunian masing-masing. Di area ruang terbuka hijau, terdapat kegiatan berkebun, yang sebetulnya hanya dimanfaatkan sebagai ruang terbuka hijau dan menanam tanaman hias, sehingga hal ini menjadikan perubahan fungsi pemanfaatan area ruang terbuka hijau. Di area blok Enggang 2 terlihat juga penghuni yang sedang duduk menunggu pada anak tangga, hal ini dikarenakan pada bangunan tidak disediakan area duduk yang dikhususkan untuk tamu/penghuni. Di area halaman blok Enggang 1, juga terdapat motor yang diparkirkan oleh penghuni. Selanjutnya pada area lantai 2 dan 3, pengamatan dilakukan pada koridor bangunan, terlihat kegiatan menjemur pada bagian atau koridor depan kamar penghuni hal ini dikarenakan luas ruang jemur yang telah disediakan tidak memadai, sehingga aktivitas dilakukan pada fasilitas bangunan yang tidak sesuai dengan kegunaan. 



Gambar 10. Place Centered Mapping Hari Minggu

Sumber: Penulis, 2021
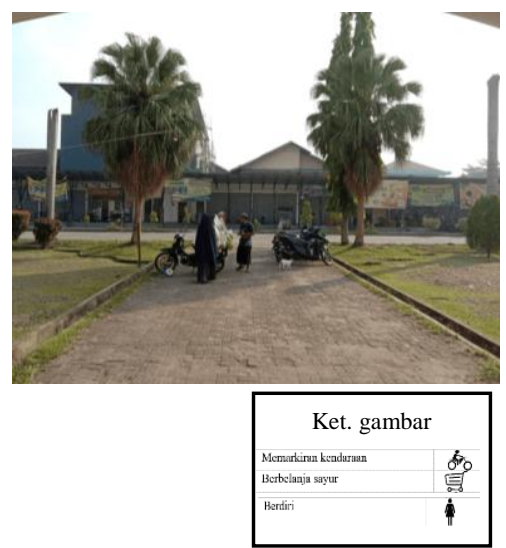

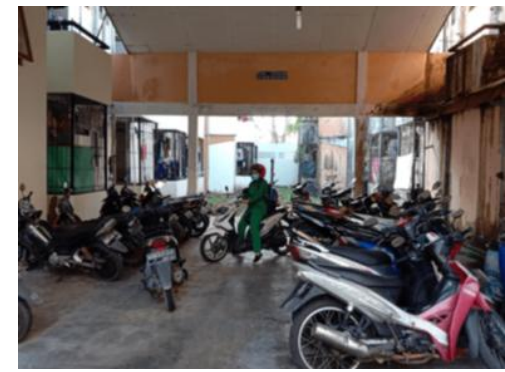

Ket. gambar Mecnunkinun keadersum
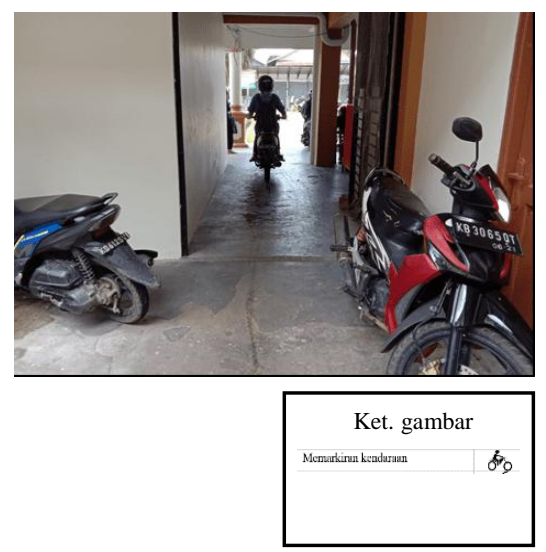

Gambar 11. Penghuni Berbelanja dan Memarkirkan Kendaraan

Sumber: Penulis, 2021

Gambar 11 menunjukkan alur kegiatan pada setiap lantai bangunan Rusunawa putri Universitas Tanjungpura. Hari senin, dari data lapangan didapatkan ada beberapa ruang digunakan sesuai dengan penggunaannya, namun ada juga yang ditempati tidak sesuai penggunaannya. Kegiatan pada hari senin lebih sering dilakukan pada kawasan lantai 1 bangunan rusunawa. Penghuni rusunawa melakukan aktivitas rutin seperti kegiatan berangakat kuliah, sehingga aktivitas banyak terlihat di parkiran. Area parkiran kendaraan terlihat tidak beraturan karena penghuni meletakkan kendaraannya sembarangan, hal ini dikarenakan pada bangunan tidak didesain lahan khusus parkir. Penghuni juga melakukan kegiatan berdiri dan duduk didepan tangga, dengan aktivitas menunggu, aktivitas tersebut dapat mengganggu penghuni lainnya yang sedang melewati sirkulasi tangga bangunan, hal ini dikarenakan pada bangunan tidak tersedia ruang atau tempat duduk bagi penghuni yang membutuhkan fasilitasnya. Aktivitas rutin yang dilakukan penghuni juga menyapu koridor pada bagian depan tepat hunian mereka masing-masing. Kegiatan menjemur baju juga dilakukan pada hari senin, aktivitas tersebut dilakukan pada ruang serbaguna pada bangunan, hal ini dikarenakan pada ruang penghuni memiliki luasan yang tidak cukup untuk menjemur baju yang ditinggali oleh 3 orang dalam satu ruang hunian. Oleh karena itu, adanya fasilitas tempat cuci yang dapat digunakan secara umum perlu dipenuhi, dengan kapasitas yang mencukupi para penghuni disetiap lantai, serta penghuni pada lantai 2 dan 3 tidak perlu lagi untuk menjemur di lantai 1. Lantai 2 dan 3 tidak terlihat aktivitas yang aktif dilakukan pada bangunan, karena penghuni sedang melakukan kegiatan perkuliahan didalam ruangan. 

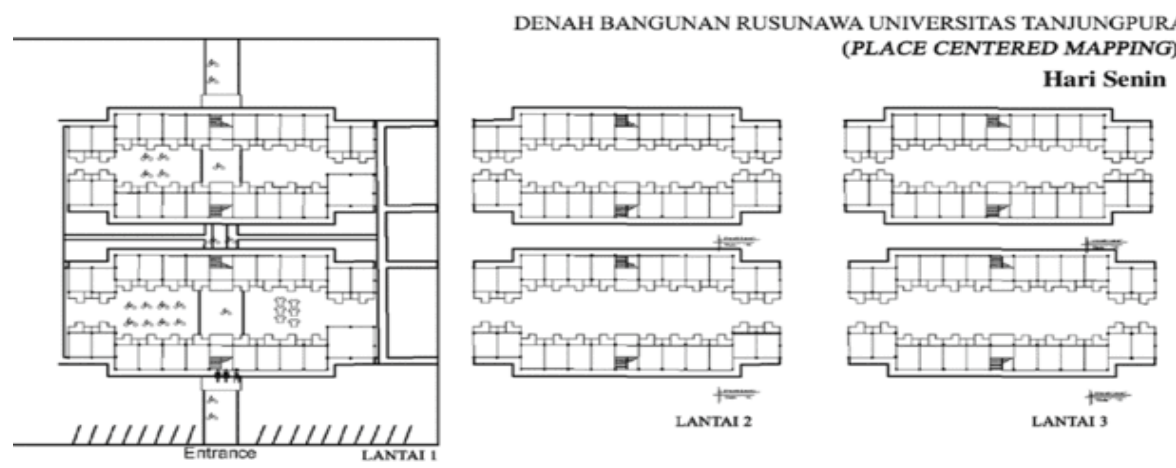

Gambar 12. Place Centered Mapping Hari Senin Sumber: Penulis, 2021
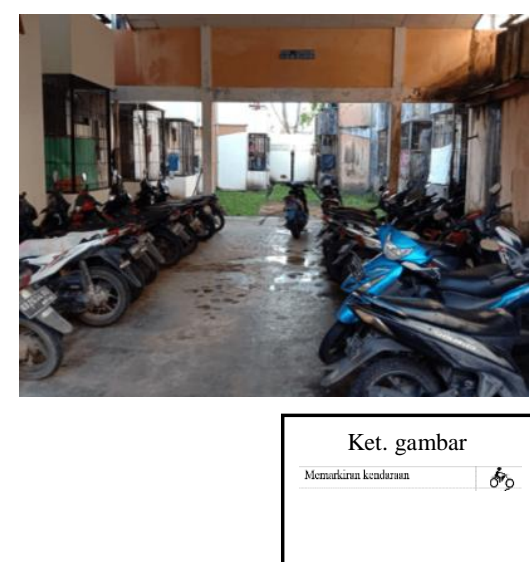
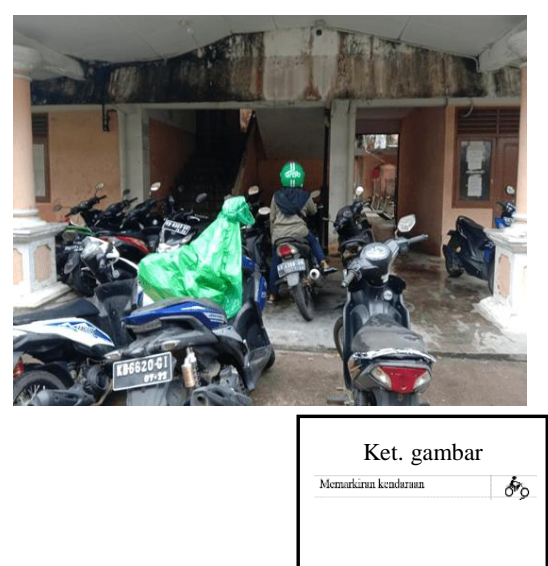

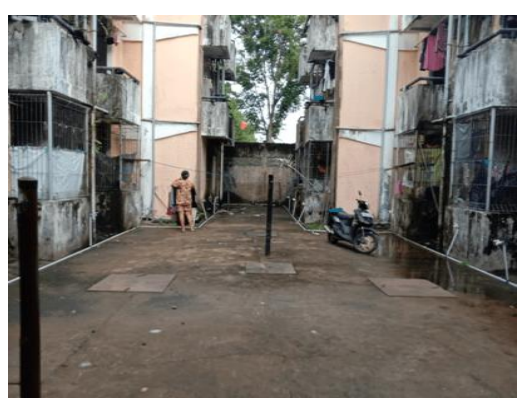

Ket. gambar Menjemur baju

Gambar 13. Parkiran Kendaraan Penghuni dan Penghuni Menjemur Pakaian

Sumber: Penulis, 2021

\section{Evaluasi Pasca Huni}

Setelah dilakukan analisis dari hasil space syntax dan place centerd mapping, maka dilakukan evaluasi pasca huni dengan memperhatikan 3 variabel yaitu sirkulasi, dimensi, dan fleksibilitas dan fungsi bangunan.

\section{A. Sirkulasi}

Usulan desain yang dilakukan adalah dengan memberikan 3 akses masuk utama yaitu pada area $\mathrm{A}$, area $\mathrm{B}$, dan area $\mathrm{C}$. Area A merupakan akses masuk pada jalan utama dekat dengan masa bangunan blok enggang 1 dan blok enggang 2. Area B merupakan akses masuk yang berdekatan dengan blok ruai 1 dan blok ruai 2 . Area $\mathrm{C}$ merupakan akses masuk alternatif yang dapat digunakan sebagai kepentingan umum, contohnya orang yang ingin mengantar galon, orang yang berjualan sayur, dan akses masuk yang menunjang kegiatan atau aktivitas penghuni bangunan. Namun, adanya akses pada area $\mathrm{C}$ ini tidak diperuntukkan bagi penghuni yang memiliki kendaraan, agar sirkulasi bangunan lebih efektif. Berikut adalah gambaran usulan desain. 


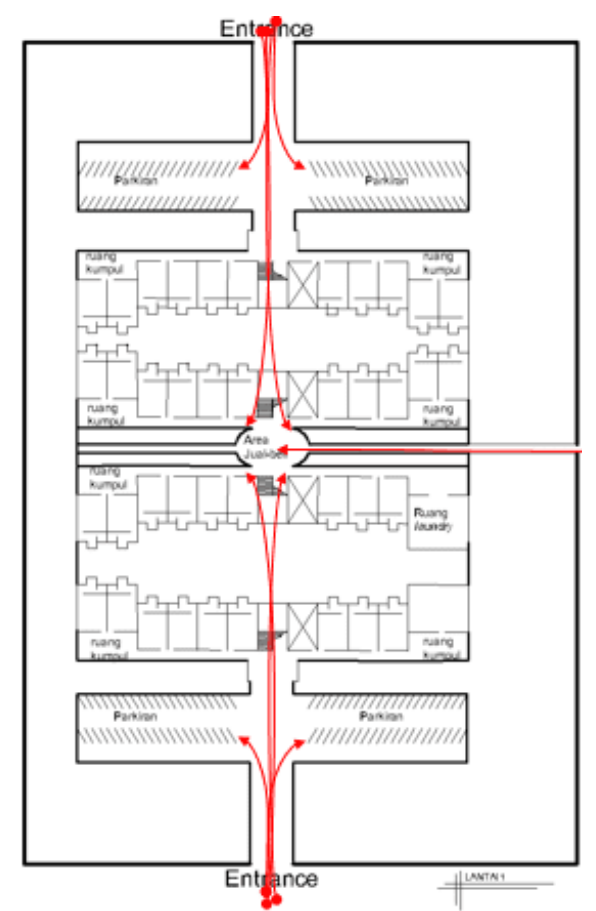

Gambar 14. Usulan Desain Sirkulasi Bangunan Rusunawa Universitas Tanjungpura

Sumber: Penulis, 2021

\section{B. Dimensi}

Permasalahan terjadi pada dimensi ruang jemur yang memiliki ukuran $1 \mathrm{~m}$ x $0.80 \mathrm{~m} / \mathrm{kamar}$ penghuni yang ditempati oleh 3-4 orang penghuni. Hal ini didasari oleh penghuni yang tidak memiliki jadwal tentu untuk mencuci baju, sehingga pelu adanya evaluasi pasca huni dalam mengatasi permasalahan tersebut. Evaluasi pada dimensi ruang jemur pada hunian penghuni tidak mudah untuk dilakukan secara makro atau mengubah secara keseluruhan bangunan, namun dalam hal ini bisa memanfaatkan sistem penjadwalan mencuci atau pada usulan desain yang menyediakan ruang laundry untuk memfasilitasi aktivitas penghuni. Ruang laundry disediakan pada ruang di rusunawa itu sendiri yang berada dilantai 1 dengan memanfaatkan ruang usaha, ukuran $42 \mathrm{~m}^{2}$ dapat menampung fasilitas yang menunjang di dalamnya. Berikut adalah gambaran usulan desain. 


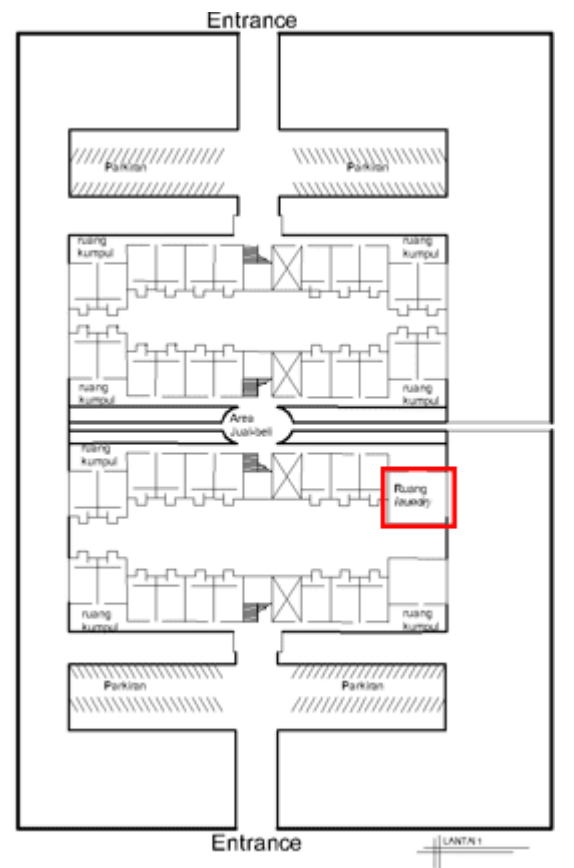

Gambar 15. Usulan Desain Ruang Laundry Bangunan Rusunawa Universitas Tanjungpura Sumber: Penulis, 2021

\section{Fleksibelitas Perubahan dan fungsi}

Permasalahan pada fungsi bangunan juga terjadi pada fasilitas prasara bangunan, pada ruang serbaguna digunakan sebagai tempat parkir kendaraan bermotor, hal ini mengganggu aktifitas pada bangunan seperti peletakan kendaraan sembarangan. Berdasarkan permasalahan tersebut maka perlu adanya evaluasi pasca huni berupa usulan desain dengan menempatkan area parkiran pada halaman bangunan rusunawa. Area parkir mempertimbangkan juga dengan jumlah penghuni yang memiliki motor. Terdapat 160 area yang dapat menampung kendaraan motor, dengan luasan 4 meter x 16 meter. Area parkiran pada bangunan didesain dengan pemberian atap agar kendaraan aman dari panas maupun hujan. Berikut adalah usulan desain tempat parkir pada bangunan Rusunawa.

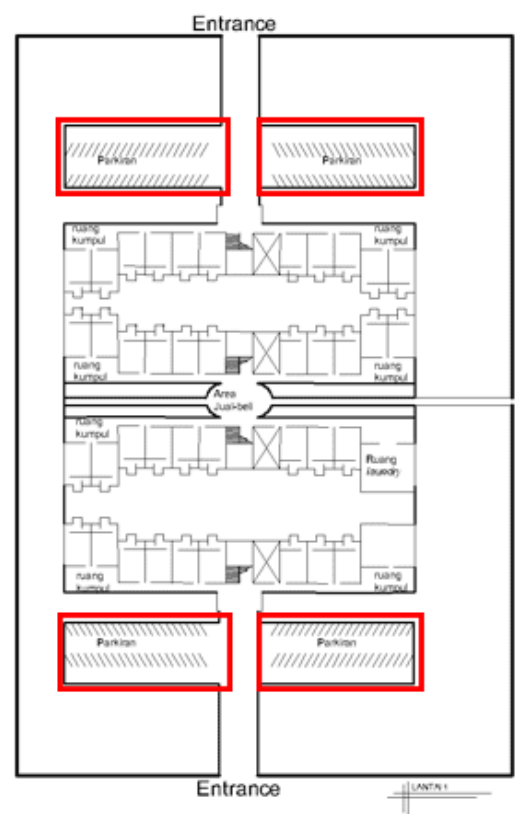

Gambar 16. Usulan Desain Tempat Parkir Bangunan Rusunawa Universitas Tanjungpura

Sumber: Penulis, 2021 


\section{Kesimpulan}

Bangunan Rusunawa Universitas Tanjungpura telah dilakukan evaluasi pasca huni, dari hasil evaluasi ditemukan beberapa masalah terkait aspek fungsional pada bangunan yaitu, sirkulasi, dimensi, dan fleksibilitas perubahan dan fungsi bangunan. Sehingga perlu dilakukan perbaikan desain terkait bangunan rusunawa Universitas Tanjungpura. Solusi atau usulan desain yang dihasilkan terlihat pada bagian sirkulasi keluar masuk pada bangunan, penambahan ruang laundry pada bangunan, kemudian penambahan ruang parkir pada bangunan rusunawa.

\section{Ucapan Terima Kasih}

Puji Syukur atas nikmat dan karunia dari Allah Subhanahu Wa Ta'alaa sehingga bisa melancarkan penyelesaian jurnal ini. Terima kasih kepada orang tua yang telah memberi dukungan dan motivasi selama proses penyelesaian jurnal, kepada para dosen pembimbing Skripsi yaitu bapak M. Ridha Alhamdani ST., M.Sc selaku pembimbing utama, Bapak Ir. Rudiyono MT selaku pembimbing kedua yang telah memberikan kritik dan saran untuk penulis.

\section{Daftar Acuan}

Fatila, I. (2019). Perancangan Apartemen dengan Konsep Modern Living Style di Kota Bandung. Skripsi. Institut Teknologi Nasioanl. Bandung

Fitria, T. A. (2018). Pengaruh Seting Ruang Terhadap Perilaku Pengguna Dengan Pendekatan Behavioral Mapping. Jurnal Arsitektur Dan Perencanaan (JUARA), 1(2), 183-206. https://doi.org/10.31101/juara.v1i2.775

Harianto, C \& Kwanda, T. (2016). Apartemen Mahasiswa Surabaya. Vol. IV, No.2, (2016), 609-616. Universitas Kristen Petra. Surabaya

Hillier. B (2007). “Space in The Machine: A Configurational Theory of Architecture”. London: Press Syndicate of The University of Cambridge

Hillier, B. (2012). "Studying cities to learn about minds: some possible implications of space syntax for spatial cognition”. Environment and Planning B: Planning and Design, 39, pp.12-32

Kurniadi, F., Sari, D. P., \& Wibowo, T. (2020). Setting Perilaku Dalam Evaluasi Purna Huni (Eph) Gedung Direktorat Politeknik Negeri Pontianak. Langkau Betang: Jurnal Arsitektur, $7(2), \quad 134$. https://doi.org/10.26418/lantang.v7i2.40699

Natalia, R., Trisnawati, E., Lazmi, N. A. (2019). Evaluasi Purna Huni Di Perumahan Condongcatur Ditinjau dari Aspek Penggunaan dan Perubahan Ruang. NALARs Jurnal Arsitektur Volume 18 Nomor 1 Januari 2019: 35-44 https://doi.org/10.24853/nalars.18.1.35-44 p-ISSN 1412-3266/e-ISSN 2549-6832

Mulia, R. (2012). Evaluasi Keandalan Bangunan Rusunawa Unnes Ditinjau Dari Persepsi Mahasiswa Yang Menghuninya. Jurnal Teknik Sipil Dan Perencanaan, 14(1), 51-60. https://doi.org/10.15294/jtsp.v14i1.7104

Pandelaki, E. E. (2015). Faktor-faktor Pembentuk Kinerja Spasial Rumah Susun Kaitannya dengan Kepuasan Penghuni. $15,85-106$

Prawitasari, F. (2020). Evaluasi Pasca Huni Huntap Pagerjurang Ditinjau Dari Aspek Fungsional. Sustainable, Planning and Culture (SPACE) : Jurnal Perencanaan Wilayah Dan Kota, 1(2), 6-14. https://doi.org/10.32795/space.v1i2.583

Sekretariat Negara Republik Indonesia. (1985). Undang-Undang Nomor 16 Tahun 1985 tentang Rumah Susun. Jakarta: Sekretariat Negara Republik Indonesia

Siregar, J. P. (2014). Metodologi Dasar Space Syntax Dalam Analisis Konfigurasi Ruang. Jurusan Perencanaan Wilayah dan Kota. Malang: Fakultas Teknik Universitas Brawijaya

Sommer, R and Sommer, B. (1980). Behavior Mapping: Practical Guide To Behavior Research. New York: Oxford University Press

Sudibyo, S. (1989). Aspek Fungsi dan Teknis Post Occupancy Evaluation dan Beberapa Metodologi Penelitian. Seminar Pengembangan Metodologi Post Occupancy Evaluation. Jakarta: Usakti

Turner, A. (2001). 'A program to perform visibility graph analysis'. In J. Peponis, J. Wineman \& S. Bafna (Eds.), Proceedings of the Third International Space Syntax Symposium. Atlanta, U.S.A: Georgia Institute of Technology

Wijaya, Dimas P. H., Subhan, R. (2018). Evaluasi Purna Huni Alun-Alun Kapuas Kota Malang. Malang: Unversitas Brawijaya 